Article

\title{
Emission Properties of Diblock Copolymers Composed of Poly(ethylene glycol) and Dense 1,2,3-Triazole Blocks
}

\author{
Yanqiong Yang, Asami Mori and Akihito Hashidzume *(D) \\ Department of Macromolecular Science, Graduate School of Science, Osaka University, 1-1 Machikaneyama-cho, \\ Toyonaka, Osaka 560-0043, Japan \\ * Correspondence: hashidzume@chem.sci.osaka-u.ac.jp; Tel.: +81-6-6850-8174
}

Received: 4 June 2019; Accepted: 24 June 2019; Published: 26 June 2019

check for updates

\begin{abstract}
This article describes a new block copolymer (EGm- $b$-AP $n$, where $m$ and $n$ denote the degrees of polymerization) of poly(ethylene glycol) (PEG) and poly(1,4-(1-H-1,2,3-triazolylene)methylene) prepared by copper(I)-catalyzed azide-alkyne cycloaddition (CuAAC) polymerization of 3-azido1-propyne (AP) in the presence of PEG carrying a propargyl moiety. The EGm- $b$-APn samples are well soluble in polar organic solvents. Unexpectedly, we observed that solutions of EGm- $b$-APn in $\mathrm{N}, \mathrm{N}$-dimethylformamide emitted fluorescence. We systematically studied absorption and emission properties of the block copolymers. The experimental data have exhibited that AP $n$ block is an intrinsic fluorophore. Interestingly, the emission of EGm- $b$-APn can be easily tuned from ultraviolet to green fluorescence by changing the excitation wavelength. This enables fine-tuning of its optical property without the need of changing the chromophore. Moreover, the block copolymers show a fluorescence response to metal ions (e.g., $\mathrm{Cu}^{2+}$ ). Our discoveries contribute to the fundamental understanding of the optical properties of dense triazole-based polymer and raise intriguing prospects for fabricating novel emissive triazole-based materials.
\end{abstract}

Keywords: emission properties; diblock copolymer; dense 1,2,3-triazole block; poly(ethylene glycol) block; copper(I)-catalyzed azide-alkyne cycloaddition polymerization

\section{Introduction}

1,2,3-Triazole is an intriguing nitrogen-rich aromatic heterocycle possessing a large dipole moment [1-3]. 1,2,3-Triazoles are formed from azides and alkynes by Huisgen cycloaddition [4,5], one of 1,3-dipolar cycloaddition reactions. It is known that Huisgen cycloaddition proceeds regioselectively to form 1,4-disubstituted-1,2,3-triazoles in the presence of copper(I) compounds [6-8]. This reaction is called copper(I)-catalyzed azide-alkyne cycloaddition (CuAAC), which provides a high efficiency even in the presence of various functional groups without protection. Consequently, CuAAC has been one of the most important reactions in "click chemistry" $[9,10]$. On the basis of the structural features [2,11], 1,2,3-triazole acts as noncovalent interaction sites through coordination bonding, $\pi-\pi$ stacking, and dipole-dipole interaction [11-15]. Some examples have been reported on functional polymers containing 1,2,3-triazole units. Polymer-carrying 1,2,3-triazole moieties can be utilized for gelation [16], sensing [17], and control of clouding point [18] through coordination bonding and solubility control [14], controlled release [19], and tough network polymer [20] through $\pi-\pi$ stacking. Therefore, polymers composed of denser 1,2,3-triazole moieties are highly promising for new functional polymers that exhibit characteristic interactions or associations.

In our previous work, we conducted CuAAC polymerization of 3-azido-1-propyne (AP) and 3-azido-1-butyne $(\mathrm{AB})$ to form oligomers possessing a number of 1,2,3-triazole moieties linked through 
a carbon atom [21]. To the best of our knowledge, these oligomers of $\mathrm{AP}$ and $\mathrm{AB}$ are ones possessing the densest 1,2,3-triazole moieties in the backbone. The $\mathrm{AP}$ and $\mathrm{AB}$ oligomers are thus promising as functional polymers based on the properties of 1,2,3-triazole. The dense 1,2,3-triazole oligomers were insoluble in common organic solvents presumably because of strong dipole-dipole interaction, although they were well soluble in strong acids (e.g., concentrated sulfuric acid, nitric acid, and hydrochloric acid). This observation indicates that protonation makes the oligomers soluble. The AP oligomer was thus quarternized with methyl iodide to obtain an oligomer soluble in polar organic solvents [22]. Since the quarternized oligomer possesses dense quaternized 1,2,3-triazole moieties, it can be expected to be a precursor of polymeric ionic liquid [23-25].

Recently, we have synthesized a diblock copolymer (EGm-b-APn, $m$ and $n$ denote the degrees of polymerization (DP)) of poly(ethylene glycol) (PEG) and dense 1,2,3-triazole blocks to investigate the properties of AP oligomer in solution. The EGm-b-APn samples obtained were well soluble in water and other polar solvents. Contrary to our expectation, these diblock copolymer samples emitted fluorescence in $N, N$-dimethylformamide (DMF). EGm-b-AP $n$ is fluorescent by itself although APn block, in which 1,2,3-triazole moieties are connected through a methylene, is not conjugated. Since fluorescent polymers have been widely applied to important fields (e.g., molecular sensors [26-28], nonlinear optical materials [28,29], and organic electroluminescence [28,30]), a new type of fluorescent polymers should be developed. In this study, we have investigated photophysical properties of $\mathrm{EG} m-b-\mathrm{AP} n$ by absorption and steady-state fluorescence spectroscopies. We have also discussed the fluorescence behavior of $\mathrm{EG} m-b-\mathrm{AP} n$ by comparing the experimental data with the results of density functional theory calculation. We have further examined the fluorescence behavior of EGm-b-APn responsive to external stimuli (i.e., metal ions).

\section{Materials and Methods}

\subsection{Materials}

3-Bromo-1-propyne (BrP), sodium azide $\left(\mathrm{NaN}_{3}\right)$, copper(II) sulfate pentahydrate $\left(\mathrm{CuSO}_{4} \cdot 5 \mathrm{H}_{2} \mathrm{O}\right)$, and sodium (+)-ascorbate (NaAsc) were purchased from FUJIFILM Wako Pure Chemical Co. (Osaka, Japan). Poly(ethylene glycol) (PEG) monomethyl ether $\left(M_{\mathrm{n}} \sim 750\right.$ and 2000, EG18 and EG45, respectively) and $N, N$-dimethylformamide (DMF) $(\geq 99.9 \%)$ were purchased from Sigma-Aldrich (St. Louis, MO, USA). Solvents (e.g., acetone, toluene, dichloromethane, diethyl ether, and DMF), were purchased from FUJIFILM Wako Pure Chemical Co. (Osaka, Japan). Water was purified with a Millipore Milli-Q system. All the reagents were used without further purification.

\subsection{Measurements}

${ }^{1} \mathrm{H}$ NMR spectra were recorded on a JEOL JNM ECA500 spectrometer using $\mathrm{CDCl}_{3}$ or dimethyl sulfoxide- $d_{6}$ (DMSO- $d_{6}$ ) as a solvent. Chemical shifts were referenced to the solvent value (7.26 and $2.50 \mathrm{ppm}$ for $\mathrm{CDCl}_{3}$ and DMSO- $d_{6}$, respectively). Size exclusion chromatography (SEC) measurements were carried out at $40^{\circ} \mathrm{C}$ on a TOSOH HLC-8320GPC equipped with a TOSOH TSKgel SuperAWM-H column, using dimethyl sulfoxide (DMSO) containing $10 \mathrm{mM} \mathrm{LiBr}$ as eluent at a flow rate of $0.4 \mathrm{~mL} \mathrm{~min}^{-1}$. Molecular weights were calibrated with PEG and poly(ethylene oxide) (PEO) standards (Scientific Polymer Products, Inc., Ontario, NY, USA). All sample solutions for SEC were filtrated with a DISMIC-13JP PTFE $0.50 \mu \mathrm{m}$ filter (ADVANTEC, Tokyo, Japan) just prior to injection. UV-Vis absorption spectra were collected on a HITACHI U-4100 spectrophotometer by using a $1.0 \mathrm{~cm}$ path length quartz cuvette at room temperature. Fluorescence measurements were performed on a HITACHI F-2500 equipped with a single cuvette reader at room temperature. The slit widths for both the excitation and emission sides were kept at $5.0 \mathrm{~nm}$ during measurement. Absolute quantum yields $(\Phi)$ were evaluated with a Hamamatsu Photonics C9920-02 absolute photoluminescence (PL) quantum yield measurement system. Pulse field gradient spin-echo (PGSE) NMR data were obtained on a Bruker AVANCE 700 NMR spectrometer at $30^{\circ} \mathrm{C}$ using $N, N$-dimethylformamide- $d_{7}$ (DMF- $d_{7}$ ) as a solvent. 
The bipolar pulse pair stimulated echo (BPPSTE) sequence was applied [31-33]. The strength of pulsed gradients $(g)$ was increased from 0.96 to 47.2 gauss $\mathrm{cm}^{-1}$. The time separation of pulsed field gradients $(\Delta)$ and their duration $(\delta)$ were 0.05 and $0.004 \mathrm{~s}$, respectively. The sample was not spun, and the airflow was disconnected. The shape of the gradient pulse was rectangular, and its strength was varied automatically during the course of the experiments.

\subsection{Preparation of Monopropargyl-Terminated Poly(ethylene glycol) (EGm-P)}

A typical procedure for EGm-P is described below [34].

EG45 $(15.02 \mathrm{~g}, 7.5 \mathrm{mmol})$ was added in toluene $(50 \mathrm{~mL})$ with stirring at room temperature for $0.5 \mathrm{~h}$ to make sure that all the EG45 was dissolved in toluene. Then $\mathrm{NaOH}(1.83 \mathrm{~g}, 45.8 \mathrm{mmol})$ and $\mathrm{BrP}$ $(1.2 \mathrm{~mL}, 15.0 \mathrm{mmol})$ were added. After stirring for $4 \mathrm{~h}, \mathrm{BrP}(1.2 \mathrm{~mL}, 15.0 \mathrm{mmol})$ and $\mathrm{NaOH}(1.80 \mathrm{~g}$, $45.0 \mathrm{mmol}$ ) were further added to the reaction mixture with continuous stirring for $26 \mathrm{~h}$. The colorless precipitate was removed from the reaction mixture by filtration, and the solvent was then removed under reduced pressure. The residue was dissolved in an aqueous solution of $\mathrm{NaCl}(5.1 \mathrm{wt} \%, 100 \mathrm{~mL})$. Then the product was extracted from the aqueous solution with $\mathrm{CH}_{2} \mathrm{Cl}_{2}(3 \times 50 \mathrm{~mL})$. The organic layers were combined. The combined organic phase was washed with an aqueous solution of $\mathrm{NaCl}$ $\left(5.1 \mathrm{wt} \%, 2 \times 100 \mathrm{~mL}\right.$ ). After drying the organic phase with anhydrous $\mathrm{MgSO}_{4}$, the $\mathrm{MgSO}_{4}$ was removed by filtration. The solvent was removed under reduced pressure to obtain crude product. Finally, the product was purified by reprecipitation with $\mathrm{CH}_{2} \mathrm{Cl}_{2}$ and hexane twice. The final product was recovered as pale yellow gel after drying under vacuum at $45^{\circ} \mathrm{C}$ for $24 \mathrm{~h}$; yield was $13.1 \mathrm{~g}(86.4 \%)$.

\subsection{Preparation of EGm-b-APn Block Copolymers}

A typical example of the preparation of diblock copolymers of PEG and dense 1,2,3-triazole blocks (EGm-b-APn, where $m$ and $n$ denote the degrees of polymerization (DP)) is described below.

A solution of EG45-P (2.52 g, $1.25 \mathrm{mmol})$ in DMF (5 mL), $\mathrm{CuSO}_{4} \cdot 5 \mathrm{H}_{2} \mathrm{O}(0.030 \mathrm{~g}, 0.125 \mathrm{mmol})$, and NaAsc $(0.050 \mathrm{~g}, 0.25 \mathrm{mmol})$ were added to a $100 \mathrm{~mL}$ flask under a nitrogen atmosphere. The mixture was stirred for $5 \mathrm{~min}$. Then, $\mathrm{NaN}_{3}(1.95 \mathrm{~g}, 30 \mathrm{mmol})$ and $\mathrm{BrP}(2.8 \mathrm{~mL}, 25 \mathrm{mmol}, 80 \mathrm{wt} \%$ in toluene) were added to the reaction mixture. The reaction mixture was warmed with an oil bath at $80^{\circ} \mathrm{C}$ with stirring. After $72 \mathrm{~h}$, the reaction mixture was added to DMF $(50 \mathrm{~mL})$. The precipitate was removed by filtration. The solution was then passed through a neutral $\mathrm{Al}_{2} \mathrm{O}_{3}$ column. The volatile fraction was removed under reduced pressure. The polymer obtained, EG45-b-AP22, was purified by reprecipitation by using pairs of solvents (i.e., a DMF/ $\mathrm{CH}_{2} \mathrm{Cl}_{2}(1 / 20, v / v)$ mixed solvent and acetone three times). The final product was dried at $80^{\circ} \mathrm{C}$ under vacuum; brown solid, $1.2 \mathrm{~g}, 34.9 \%$.

\subsection{Density Functional Theory (DFT) Calculations}

To investigate the highest-occupied and lowest-unoccupied molecular orbitals (HOMO and LUMO, respectively), DFT calculations were carried out for model systems of EGm-b-APn using the Gaussian 09 program [35]. In all the calculations, DFT with B3LYP functional was used, and 6-31+G(d) basis sets were applied for the hydrogen, carbon, nitrogen, and oxygen atoms. All the geometries of the model systems were fully optimized.

\section{Results and Discussion}

\subsection{Preparation of EGm-b-APn Block Copolymers}

Samples of EGm-b-APn were prepared by CuAAC polymerization of 3-azido-1-propyne (AP) in the presence of PEG modified with a propargyl group at one end (EGm-P) (Scheme 1). Since the reaction mixture of this procedure contained not only EGm-b-APn diblock copolymer but also AP homopolymer and the remaining EGm-P, EGm- $b$ - $\mathrm{AP} n$ samples were purified by reprecipitation using an appropriate combination of good and poor solvents to remove the homopolymers. Table 1 summarizes the basic characteristics of the four EGm-b-APn samples obtained. These samples were characterized by SEC 
and ${ }^{1} \mathrm{H}$ NMR as can be seen in Figures S1-S3 in the Supporting Information. Our previous work has demonstrated that AP homopolymer is insoluble in all the common solvents examined, including DMF, DMSO, $N$-methylpyrrolidone (NMP), methanol, acetone, THF, chloroform, and toluene [21,22]. Thus, the solubility of the EGm-b-APn diblock copolymer samples was examined, and the results are summarized in Table 2. Due to the PEG block, the EGm-b-APn samples were soluble in many common solvents. The samples were especially well soluble in polar organic solvents.

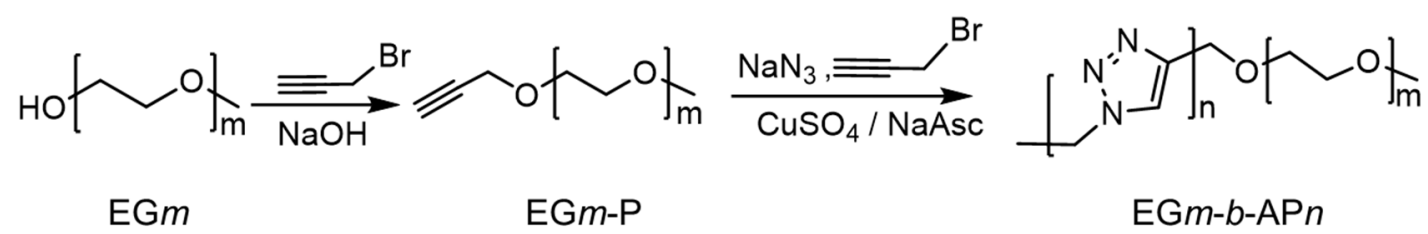

Scheme 1. Synthetic route of EGm-P and EGm-b-APn.

Table 1. Molecular characteristics of EGm-b-APn samples prepared by copper(I)-catalyzed azide-alkyne cycloaddition (CuAAC) polymerization.

\begin{tabular}{cccc}
\hline Polymer Code $^{\mathbf{a}}$ & $\boldsymbol{M}_{\mathbf{n}} \times \mathbf{1 0}^{-\mathbf{3} \mathbf{b}}$ & $\boldsymbol{M}_{\mathbf{n}} \times \mathbf{1 0}^{-\mathbf{3} \mathbf{c}}$ & $\boldsymbol{M}_{\mathbf{w}} / \boldsymbol{M}_{\mathbf{n}}{ }^{\mathbf{c}}$ \\
\hline EG18- $b$-AP4 & 1.1 & 1.5 & 1.26 \\
EG18- $b$-AP12 & 1.8 & 3.3 & 1.98 \\
EG45- $b$-AP6 & 2.5 & 2.7 & 1.40 \\
EG45- $b$-AP22 & 3.6 & 2.5 & 2.37 \\
\hline
\end{tabular}

a The numbers denote DP determined by ${ }^{1} \mathrm{H}$ NMR spectroscopy. ${ }^{\mathrm{b}}$ Determined by ${ }^{1} \mathrm{H}$ NMR. ${ }^{\mathrm{c}}$ Determined by size exclusion chromatography (SEC) in DMSO at $40{ }^{\circ} \mathrm{C}$ calibrated with poly(ethylene glycol) (PEG) and poly(ethylene oxide) (PEO) standards.

Table 2. Results of solubility test for EGm-b-APn samples. ${ }^{1}$

\begin{tabular}{|c|c|c|c|c|}
\hline Solvent & EG18- $b$-AP4 & EG18- $b$-AP12 & EG45- $b$-AP6 & EG45- $b$-AP22 \\
\hline water & ++ & + & ++ & + \\
\hline methanol & + & - & ++ & + \\
\hline acetic acid & ++ & ++ & ++ & ++ \\
\hline NMP & ++ & ++ & ++ & ++ \\
\hline DMSO & ++ & ++ & ++ & ++ \\
\hline DMF & ++ & ++ & ++ & ++ \\
\hline acetonitrile & ++ & + & ++ & + \\
\hline acetone & ++ & - & + & - \\
\hline dicholromethane & ++ & ++ & ++ & + \\
\hline chloroform & ++ & ++ & ++ & + \\
\hline pyridine & ++ & ++ & ++ & + \\
\hline THF & + & - & + & - \\
\hline ethyl acetate & + & - & - & - \\
\hline toluene & - & - & - & - \\
\hline
\end{tabular}

\subsection{Emission Properties of EGm-b-APn Block Copolymers}

When a solution of EGm- $b-\mathrm{AP} n$ in DMF was measured by dynamic light scattering in order to characterize the polymer chains in the molecularly dispersed state, emission from the solution was observed. Thus, the photophysical behavior of solutions of the EGm-b-APn samples in DMF was examined by absorption and steady-state fluorescence spectroscopy. As can be seen in Figure 1a, a solution of EG45- $b$-AP22 in DMF emits blue fluorescence under irradiation with $360 \mathrm{~nm}$ UV light. Figure $1 \mathrm{~b}$ displays UV-Vis absorption spectra for solutions of the EGm-b-APn samples in DMF. These spectra exhibit absorption in the wavelength range of $270-450 \mathrm{~nm}$, which is ascribable to the dense 1,2,3-triazole block. It should be noted here that EG45-b-AP22 shows absorption bands in the near UV and visible regime of 300-500 nm, which are stronger compared to that for EG45-b-AP6. 
This observation indicates that a longer dense 1,2,3-triazole block absorbs light of a longer wavelength. Figure $1 \mathrm{c}-\mathrm{f}$ indicate steady-state fluorescence spectra for DMF solutions of EGm-b-APn with excitation at varying wavelengths from 300 to $440 \mathrm{~nm}$. These spectra exhibit that the solutions emit fluorescence of a wavelength increasing from UV to green with increasing excitation wavelength. As can be seen in Figures S4 and S5 in Supporting Information, solutions of EGm-b-APn in acetonitrile and water also emit fluorescence depending on the excitation wavelength. This may be because the EGm-b-APn samples possess a rather broad molecular weight distribution, and AP $n$ blocks of different lengths are excited at different wavelengths [36,37]. The excitation and emission bands of AP $n$ block are dependent on DP, i.e., $n$. Since EGm-P did not emit fluorescence $[38,39]$, it is likely that the emission observed is from the dense 1,2,3-triazole block. The absolute fluorescence quantum yields were evaluated for the EGm-b-APn samples in DMF, acetonitrile, and water. As listed in Table 3, the quantum yield ranges from 1.4-3.4\%, indicating that the quantum yields in DMF are higher than those in the other solvents.

(a)

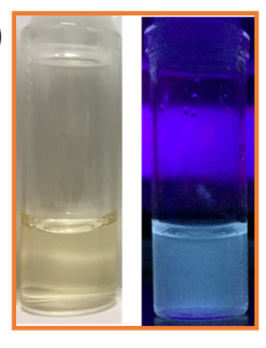

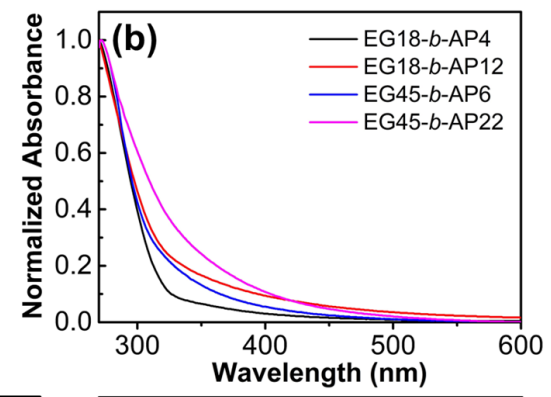
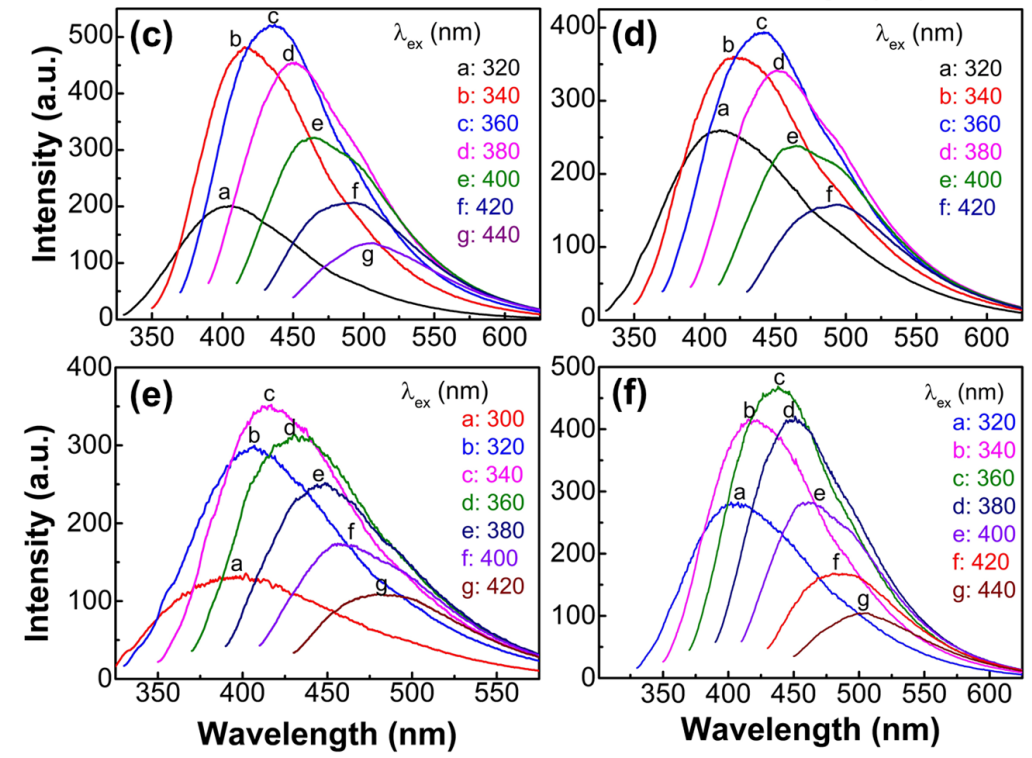

Figure 1. Photographs of EG45- $b$-AP22 in DMF at $1.0 \mathrm{~g} \mathrm{~L}^{-1}$ under visible (left) and $\mathrm{UV}(\lambda=365 \mathrm{~nm})$ light (right) (a), UV-Vis absorption spectra normalized at $270 \mathrm{~nm}$ for $0.30 \mathrm{~g} \mathrm{~L}^{-1}$ solutions of EGm-b-APn in DMF (b), and steady-state fluorescence spectra for $1.0 \mathrm{~g} \mathrm{~L}^{-1}$ solutions of EG18-b-AP4 (c), EG18-b-AP12 (d), EG45-b-AP6 (e), and EG45-b-AP22 (f) in DMF with excitation at varying wavelengths.

Table 3. Fluorescence quantum yields $(\Phi)$ for the EGm-b-APn samples in DMF, acetonitrile, and water $\left(1.0 \mathrm{~g} \mathrm{~L}^{-1}\right)$.

\begin{tabular}{cccc}
\hline \multirow{2}{*}{ Polymer Code } & \multicolumn{3}{c}{$\boldsymbol{\Phi}$} \\
\cline { 2 - 4 } & In DMF & In Acetonitrile & In Water \\
\hline EG18- $b$-AP4 & 0.034 & 0.020 & 0.018 \\
EG18- $b$-AP12 & 0.020 & - & - \\
EG45- $b$-AP6 & 0.029 & 0.019 & 0.014 \\
EG45- $b$-AP22 & 0.024 & - & - \\
\hline
\end{tabular}


Recently, aggregation-induced emission (AIE) has attracted increasing interest from researchers because of its potential application for molecular sensors [40]. Some examples of AIE from polymers possessing no aromatic moieties have been reported. It is important to know whether or not the emission observed from EGm- $b$-AP $n$ is AIE. The association behavior of EGm-b-AP $n$ was preliminarily investigated in DMF by PGSE NMR [41]. The PGSE NMR data are presented in Figure 2a. The intensity data practically obey a straight line at four different concentrations, indicative of a unimodal distribution. The unimodal distribution is confirmed by diffusion-ordered spectroscopy (DOSY) data as can be seen in Figure S4 in the Supporting Information. From the slopes of straight lines, apparent diffusion coefficients $(D)$ were evaluated and plotted in Figure $2 \mathrm{~b}$ against the polymer concentration. The diffusion coefficient $\left(D_{0}\right)$ was determined by extrapolation to zero concentration. Using the Einstein-Stokes equation, the hydrodynamic radius $\left(R_{\mathrm{H}}\right)$ was calculated to be $1.35 \mathrm{~nm}$ for EG45- $b$-AP22. The $R_{\mathrm{H}}$ value is almost the same as that for PEG of the same molecular weight, indicating that most of EG45- $b$-AP22 chains are molecularly dispersed in DMF. As discussed in a later subsection, the fluorescence intensity decreased markedly when a small amount of water was added to a solution of EGm-b-APn in DMF to induce aggregation because water is a rather poor solvent for EGm-b-APn. This observation confirms that the emission observed for DMF solutions is from $\mathrm{EG} m-b-\mathrm{AP} n$ in the molecularly dispersed state.
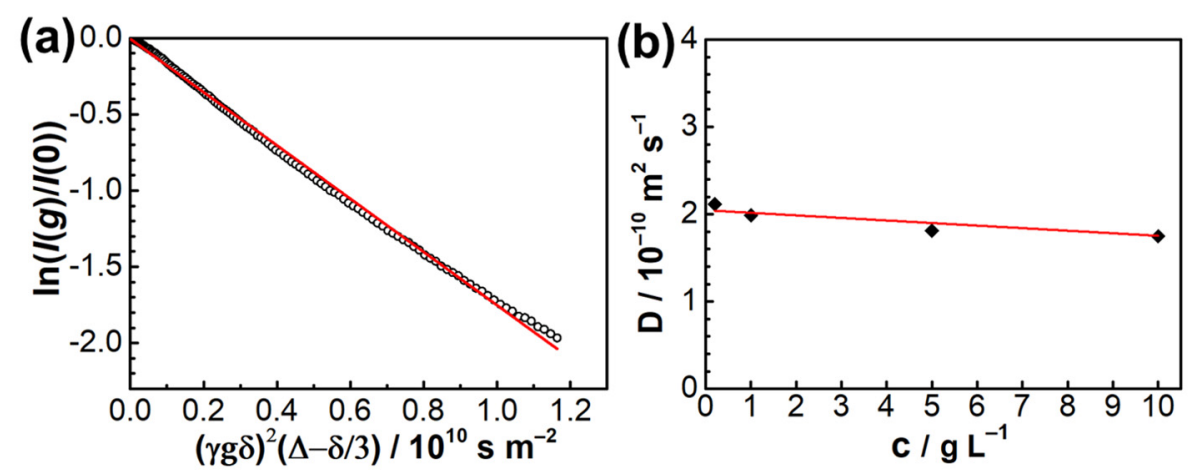

Figure 2. Pulse field gradient spin-echo (PGSE) NMR data for $10.0 \mathrm{~g} \mathrm{~L}^{-1}$ solution of EG45- $b$-AP22 in DMF- $d_{7}(\mathbf{a})$ and the concentration dependencies of $D(\mathbf{b})$.

To understand the detail mechanism of the fluorescence observed, the HOMO and LUMO of $\mathrm{EG} m-b-\mathrm{AP} n$ were estimated by preliminary DFT calculations. As shown in Figure 3, the HOMO is located on the 1,2,3-triazole unit directly connecting the PEG block. On the other hand, the LUMO is located on the terminal 1,2,3-triazole unit. These observations indicate that the emission is from the dense 1,2,3-triazole block. The absorption and fluorescence wavelengths were also evaluated by DFT calculation, as listed in Table 4. The length of PEG block has no or only a little effect on the absorption and fluorescence wavelengths. On the other hand, as the degree of polymerization of APn block is increased from 4 to 7 , the absorption and fluorescence wavelengths become longer (i.e., a red shift). The red shift is larger for fluorescence than that for absorption. These data indicate that the absorption and fluorescence wavelengths depend on the length of APn block. It is noteworthy that the fluorescence wavelength calculated agrees well with the fluorescence maximum observed [42,43]. On the basis of these observations, it is concluded that the emission from solutions of EGm-b-APn is not AIE, and the fluorescence is from the dense 1,2,3-triazole blocks in the molecularly dispersed state. 
EG2-b-AP4 (Optimized) EG5-b-AP4 (Optimized) EG5-b-AP7 (Optimized)
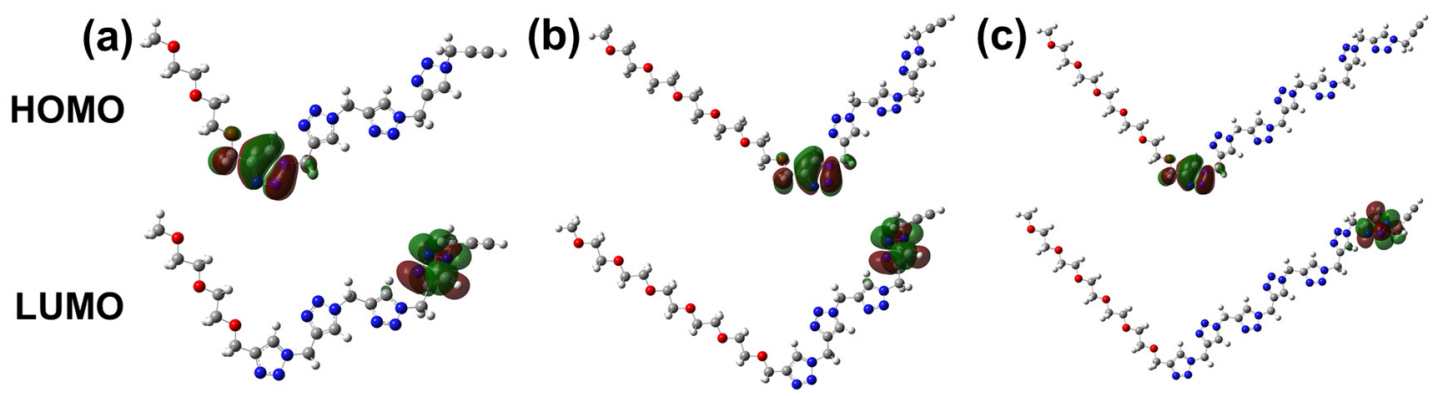

Figure 3. Optimized structures as well as the highest-occupied molecular orbitals (HOMO) and lowest-unoccupied molecular orbitals (LUMO) for EG2-b-AP4 (a), EG5-b-AP4 (b), and EG5- b-AP7 (c) obtained by DFT calculations using a B3LYP/6-31+G(d) basis set with a Gaussian'09 program (blue: N; red: O; grey: C; white: $\mathrm{H}$ ).

Table 4. Time-dependent DFT (TDDFT)-predicted properties of models of EGm- $b$-APn

\begin{tabular}{ccc}
\hline Model & Abs. $\mathbf{1} / \mathbf{n m}$ & Emission ${ }^{\mathbf{2}} / \mathbf{n m}$ \\
\hline EG2- $b$-AP4 & 231.1 & 456.6 \\
EG5-AP4 & 231.4 & 455.7 \\
EG5- $b$-AP7 & 237.1 & 473.9
\end{tabular}

${ }^{1}$ Energy (TDDFT) using the optimized structure in ground state. ${ }^{2}$ Optimization $($ TDDFT, root $=1$ ) using the optimized structure in ground state.

The effects of the solvent and polymer concentration on fluorescence behavior were examined. Figure 4a displays fluorescence spectra for EG45-b-AP22 in different solvents with excitation at $360 \mathrm{~nm}$. The block copolymer shows an emission band depending on the solvent used. When a small amount of water was added to the solution of EG45- $b$-AP22 in DMF, the fluorescence intensity decreased remarkably. As can be seen in Table 2, water is not a good solvent for EG45-b-AP22 compared to DMF and DMSO. Since our preliminary light scattering data indicated that EG45-b-AP22 forms aggregates in water (not shown), it is likely that the aggregation of EG45-b-AP22 quenches fluorescence. Figure $4 \mathrm{~b}$ exhibits fluorescence spectra for EG45- $b$-AP22 in mixed solvent of DMF and THF, a poor solvent, indicating that the fluorescence intensity decreases by increasing the THF content. As can be seen in Figure $4 \mathrm{~b}$, the fluorescence intensity decreases by increasing the polymer concentration from 1.0 to $20 \mathrm{~g} \mathrm{~L}^{-1}$. These observations confirm that aggregation quenches fluorescence.
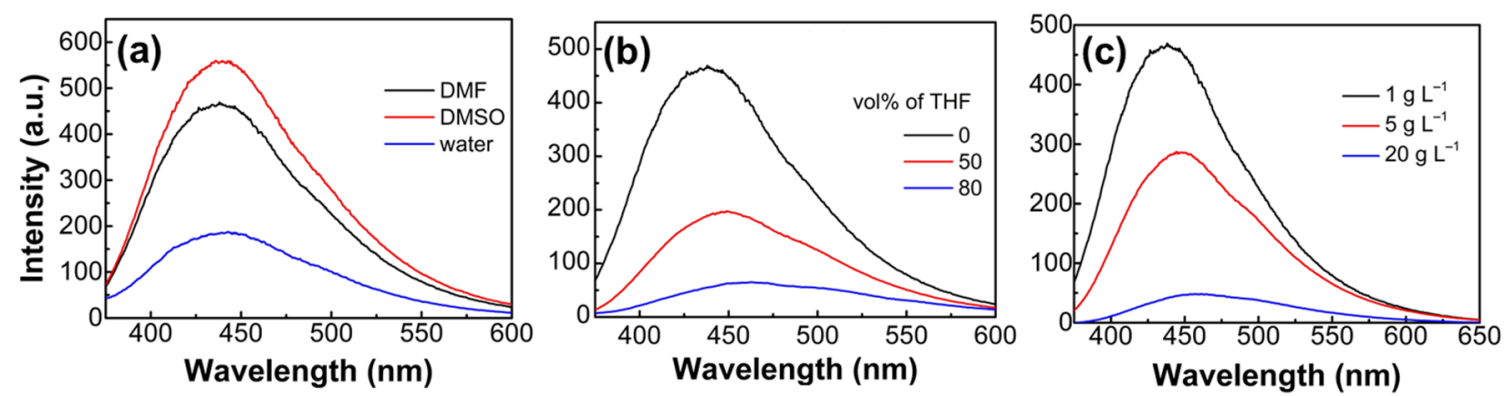

Figure 4. Steady-state fluorescence spectra for solutions of EG45- $b$-AP22 $\left(1.0 \mathrm{~g} \mathrm{~L}^{-1}\right)$ in water, DMF, and DMSO (a), in mixed solvent of DMF and THF with different THF contents (b), and in DMF at different concentrations with excitation at $360 \mathrm{~nm}$ (c).

\subsection{Metal Ion-Responsive Emission of EGm-b-APn Block Copolymers}

As described in the introduction part, it is known that 1,2,3-triazole moieties can act as metal ligands [16,44]. It is thus expected that the fluorescence behavior of EGm-b-APn diblock copolymers should be responsive to the metal ion added. In this study, the effect of the addition of $\mathrm{Na}^{+}, \mathrm{Zn}^{2+}$, 
or $\mathrm{Cu}^{2+}$ was investigated. Figure 5 shows fluorescence spectra for an aqueous solution of EG18-b-AP10 in the absence and presence of $\mathrm{Na}^{+}, \mathrm{Zn}^{2+}$, or $\mathrm{Cu}^{2+}$. In the presence of $\mathrm{Na}^{+}$or $\mathrm{Zn}^{2+}$, the fluorescence spectra are almost the same as that in the absence. In the presence of $\mathrm{Cu}^{2+}$, however, the fluorescence intensity is markedly weaker. This may be because dense 1,2,3-triazole moieties coordinate $\mathrm{Cu}^{2+}$ ions and fluorescence is quenched through the heavy metal effect. These observations indicate that the fluorescence of EGm-b-APn can be applicable to a molecular sensor of metal ions.

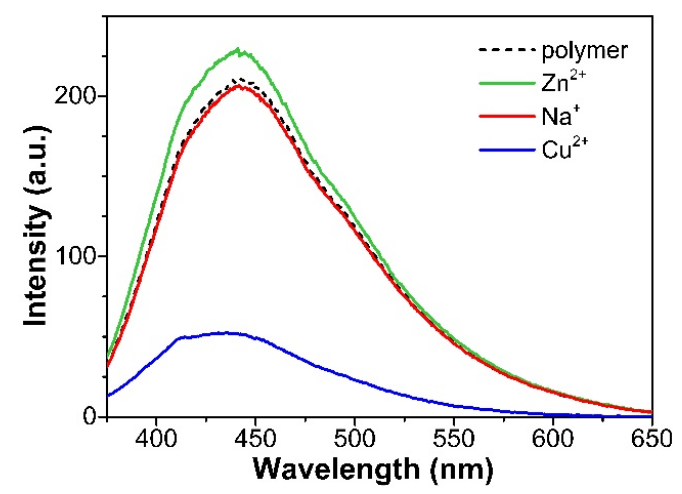

Figure 5. Steady-state fluorescence spectra for a $1.0 \mathrm{~g} \mathrm{~L}^{-1}$ aqueous solution of EG18- $b$-AP10 with excitation at $360 \mathrm{~nm}$ in the absence and the presence of $0.10 \mathrm{M} \mathrm{Na}^{+}, 0.10 \mathrm{M} \mathrm{Zn}^{2+}$, or $0.005 \mathrm{M} \mathrm{Cu}^{2+}$.

\section{Conclusions}

In conclusion, we have synthesized dense triazole-based block copolymers, EGm-b-APn, and studied their solubility and photophysical characterization in solution state. The incorporation of EGm block significantly enhanced the solubility of bock copolymers in common polar solvents. Their solubility decreases by increasing the length of AP $n$ block. Significantly, without attachment of any extra fluorophore, the as-prepared block copolymers emit fluorescence in solution state. The emission of block copolymers is tunable from ultraviolet to green fluorescence by changing the excitation wavelength presumably because a longer AP $n$ block is excited at a longer wavelength. PGSE NMR analysis and theoretical calculation indicate that the copolymers are molecularly dispersed in DMF- $d_{7}$ and $\mathrm{AP} n$ block is an intrinsic fluorophore. It is noteworthy that the emission of block copolymer is responsive to metal ions because of the interaction with dense 1,2,3-triazole blocks dependent on the ionic species. This work will afford a new aspect for fabricating novel emissive triazole-based functional materials.

Supplementary Materials: The following are available online at http://www.mdpi.com/2073-4360/11/7/1086/s1, Figure S1: SEC analysis of EGm-P and EGm-b-AP $n$ samples, Figure S2: ${ }^{1} \mathrm{H}$ NMR spectra of EG18- $b$-AP $n$ in DMSO- $d_{6}\left(500 \mathrm{MHz}, 25^{\circ} \mathrm{C}\right)$, Figure S3: ${ }^{1} \mathrm{H}$ NMR spectra of EG45- $b-\mathrm{AP} n$ in DMSO- $d_{6}\left(500 \mathrm{MHz}, 25^{\circ} \mathrm{C}\right)$, Figure S4: Steady-state fluorescence spectra for $1.0 \mathrm{~g} \mathrm{~L}^{-1}$ solutions of EG18-b-AP4 in acetonitrile (a) and water (b), Figure S5: Steady-state fluorescence spectra for $1.0 \mathrm{~g} \mathrm{~L}^{-1}$ solutions of EG45-b-AP6 in acetonitrile (a) and water (b), Figure S6: DOSY spectrum for a $10.0 \mathrm{~g} \mathrm{~L}^{-1}$ solution of EG45-b-AP22 in DMF- $d_{7}$ at $298 \mathrm{~K}$.

Author Contributions: Conceptualization, Y.Y. and A.H.; methodology, Y.Y. and A.H.; validation, Y.Y., A.M. and A.H.; formal analysis, Y.Y. and A.M.; investigation, Y.Y. and A.M.; resources, A.H.; data curation, Y.Y.; writing - original draft preparation, Y.Y. and A.H.; writing-review and editing, Y.Y. and A.H.; visualization, Y.Y.; supervision, A.H.; project administration, A.H.; funding acquisition, Y.Y. and A.H.

Funding: This research was funded partly by the Sasakawa Scientific Research Grant 2018-3035 from the Japan Science Society and JSPS Kakenhi Grant Number JP26288061.

Acknowledgments: The authors would like to express their acknowledgment to Naoya Inazumi, Graduate School of Science, Osaka University, for the PGSE NMR measurements and for his valuable suggestions. The authors thank Yuri Kamon, Department of Macromolecular Science, Graduate School of Science, Osaka University for her valuable suggestions.

Conflicts of Interest: The authors declare no conflicts of interest. 


\section{References}

1. Abboud, J.-L.M.; Foces-Foces, C.; Notario, R.; Trifonov, R.E.; Volovodenko, A.P.; Ostrovskii, V.A.; Alkorta, I.; Elguero, J. Basicity of N-H- and N-methyl-1,2,3-triazoles in the gas phase, in solution, and in the solid state-an experimental and theoretical study. Eur. J. Org. Chem. 2001, 2001, 3013-3024. [CrossRef]

2. Kolb, H.C.; Sharpless, K.B. The growing impact of click chemistry on drug discovery. Drug Discovery Today. 2003, 8, 1128-1137. [CrossRef]

3. Dehaen, W.; Bakulev, V.A. Chemistry of 1,2,3-triazoles; Springer: Cham, Switzerland, 2015.

4. Huisgen, R.; Grashey, R.; Aufderhaar, E.; Kunz, R. 1,3-Dipolar cycloadditions. XIII. Additions of nitrilimines to oximes, azines, and other cn double bonds. Chem. Ber. 1965, 98, 642-649. [CrossRef]

5. Huisgen, R. The concerted nature of 1,3-dipolar cycloadditions and the question of diradical intermediates. J. Org. Chem. 1976, 41, 403-419. [CrossRef]

6. Tornøe, C.W.; Christensen, C.; Meldal, M. Peptidotriazoles on solid phase: [1,2,3]-triazoles by regiospecific copper(I)-catalyzed 1,3-dipolar cycloadditions of terminal alkynes to azides. J. Org. Chem. 2002, 67, 3057-3064. [CrossRef] [PubMed]

7. Rostovtsev, V.V.; Green, L.G.; Fokin, V.V.; Sharpless, K.B. A stepwise huisgen cycloaddition process: Copper(I)-catalyzed regioselective "ligation" of azides and terminal alkynes. Angew. Chem. Int. Ed. 2002, 41, 2596-2599. [CrossRef]

8. Fazio, F.; Bryan, M.C.; Blixt, O.; Paulson, J.C.; Wong, C.-H. Synthesis of sugar arrays in microtiter plate. J. Am. Chem. Soc. 2002, 124, 14397-14402. [CrossRef] [PubMed]

9. Kolb, H.C.; Finn, M.G.; Sharpless, K.B. Click chemistry: Diverse chemical function from a few good reactions. Angew. Chem. Int. Ed. 2001, 40, 2004-2021. [CrossRef]

10. Lahann, J. Click chemistry for biotechnology and materials science. Wiley \& Sons: Chichester, UK, 2009.

11. Schulze, B.; Schubert, U.S. Beyond click chemistry-supramolecular interactions of 1,2,3-triazoles. Chem. Soc. Rev. 2014, 43, 2522-2571. [CrossRef]

12. McDonald, K.P.; Hua, Y.; Flood, A.H. 1,2,3-Triazoles and the expanding utility of charge neutral CH $\cdots$ anion interactions. In Anion Recognition in Supramolecular Chemistry; Gale, P.A., Dehaen, W., Eds.; Springer: Berlin, Germany, 2010; pp. 341-366.

13. Ghosh, K.; Panja, A.; Panja, S. Cholesterol appended bis-1,2,3-triazoles as simple supramolecular gelators for the naked eye detection of $\mathrm{Ag}^{+}, \mathrm{Cu}^{2+}$ and $\mathrm{Hg}^{2+}$ ions. New J. Chem. 2016, 40, 3476-3483. [CrossRef]

14. Jung, S.-H.; Ryu, J.; Sohn, D.; Lee, H.-i. Time-dependent increase in aqueous solubility caused by the gradual disruption of hydrophobic aggregation. Polym. Chem. 2012, 3, 1002-1006. [CrossRef]

15. Hua, Y.; Flood, A.H. Click chemistry generates privileged ch hydrogen-bonding triazoles: The latest addition to anion supramolecular chemistry. Chem. Soc. Rev. 2010, 39, 1262-1271. [CrossRef] [PubMed]

16. Meudtner, R.M.; Hecht, S. Responsive backbones based on alternating triazole-pyridine/benzene copolymers: From helically folding polymers to metallosupramolecularly crosslinked gels. Macromol. Rapid Commun. 2008, 29, 347-351. [CrossRef]

17. Pourghaz, Y.; Dongare, P.; Thompson, D.W.; Zhao, Y. Click functionalized poly( $p$-phenylene ethynylene)s as highly selective and sensitive fluorescence turn-on chemosensors for $\mathrm{Zn}^{2+}$ and $\mathrm{Cd}^{2+}$ ions. Chem. Commun. 2011, 47, 11014-11016. [CrossRef] [PubMed]

18. Wu, J.; Liu, W.; Han, H.; Sun, R.; Xie, M.; Liao, X. Hyperbranched poly(triazole) with thermal and metal ion dual stimuli-responsiveness. Polym. Chem. 2015, 6, 4801-4808. [CrossRef]

19. Mishra, V.; Jung, S.-H.; Park, J.M.; Jeong, H.M.; Lee, H.-i. Triazole-containing hydrogels for time-dependent sustained drug release. Macromol. Rapid Commun. 2014, 35, 442-446. [CrossRef] [PubMed]

20. Song, H.B.; Baranek, A.; Worrell, B.T.; Cook, W.D.; Bowman, C.N. Photopolymerized triazole-based glassy polymer networks with superior tensile toughness. Adv. Funct. Mater. 2018, 28, 1801095. [CrossRef] [PubMed]

21. Hashidzume, A.; Nakamura, T.; Sato, T. Copper-catalyzed azide-alkyne cycloaddition oligomerization of 3-azido-1-propyne derivatives. Polymer 2013, 54, 3448-3451. [CrossRef]

22. Nakano, S.; Hashidzume, A.; Sato, T. Quarternization of 3-azido-1-propyne oligomers obtained by copper(I)catalyzed azide-alkyne cycloaddition polymerization. Beilstein J. Org. Chem. 2015, 11, 1037-1042. [CrossRef]

23. Jourdain, A.; Serghei, A.; Drockenmuller, E. Enhanced ionic conductivity of a 1,2,3-triazolium-based poly(siloxane ionic liquid) homopolymer. ACS Macro Lett. 2016, 5, 1283-1286. [CrossRef] 
24. Nguyen, T.K.L.; Obadia, M.M.; Serghei, A.; Livi, S.; Duchet-Rumeau, J.; Drockenmuller, E. 1,2,3-Triazoliumbased epoxy-amine networks: Ion-conducting polymer electrolytes. Macromol. Rapid Commun. 2016, 37, 1168-1174. [CrossRef] [PubMed]

25. Obadia, M.M.; Drockenmuller, E. Poly(1,2,3-triazolium)s: A new class of functional polymer electrolytes. Chem. Commun. 2016, 52, 2433-2450. [CrossRef] [PubMed]

26. Toal, S.J.; Trogler, W.C. Polymer sensors for nitroaromatic explosives detection. J. Mater. Chem. 2006, 16, 2871-2883. [CrossRef]

27. Thomas, S.W.; Joly, G.D.; Swager, T.M. Chemical sensors based on amplifying fluorescent conjugated polymers. Chem. Rev. 2007, 107, 1339-1386. [CrossRef] [PubMed]

28. Liu, J.; Lam, J.W.Y.; Tang, B.Z. Acetylenic polymers: Syntheses, structures, and functions. Chem. Rev. 2009, 109, 5799-5867. [CrossRef]

29. Willets, K.A.; Nishimura, S.Y.; Schuck, P.J.; Twieg, R.J.; Moerner, W.E. Nonlinear optical chromophores as nanoscale emitters for single-molecule spectroscopy. Acc. Chem. Res. 2005, 38, 549-556. [CrossRef]

30. Yang, X.; Xu, X.; Zhou, G. Recent advances of the emitters for high performance deep-blue organic light-emitting diodes. J. Mater. Chem. C 2015, 3, 913-944. [CrossRef]

31. Stejskal, E.O.; Tanner, J.E. Spin diffusion measurements: Spin echoes in the presence of a time-dependent field gradient. J. Chem. Phys. 1965, 42, 288-292. [CrossRef]

32. Tanner, J.E.; Stejskal, E.O. Restricted self-diffusion of proteins in colloidal systems by the pulse-gradient, spin-echo method. J. Chem. Phys. 1968, 49, 1768-1777. [CrossRef]

33. Stilbs, P. Fourier transform pulsed-gradient spin-echo studies of molecular diffusion. Prog. Nucl. Magn. Reson. Spectrosc. 1987, 19, 1-45. [CrossRef]

34. Dimonie, M.; Teodorescu, M. Phase transfer catalysis synthesis of $\alpha, \omega$-diallylpoly(ethylene oxide). Makromol. Chem. Rapid Commun. 1993, 14, 303-307. [CrossRef]

35. Zhu, S.; Song, Y.; Shao, J.; Zhao, X.; Yang, B. Non-conjugated polymer dots with crosslink-enhanced emission in the absence of fluorophore units. Angew. Chem. Int. Ed. 2015, 54, 14626-14637. [CrossRef] [PubMed]

36. Qiao, Z.-A.; Huo, Q.; Chi, M.; Veith, G.M.; Binder, A.J.; Dai, S. A “ship-in-a-bottle” approach to synthesis of polymer dots@silica or polymer dots@carbon core-shell nanospheres. Adv. Mater. 2012, 24, 6017-6021. [CrossRef] [PubMed]

37. Zhu, S.; Wang, L.; Zhou, N.; Zhao, X.; Song, Y.; Maharjan, S.; Zhang, J.; Lu, L.; Wang, H.; Yang, B. The crosslink enhanced emission (CEE) in non-conjugated polymer dots: From the photoluminescence mechanism to the cellular uptake mechanism and internalization. Chem. Commun. 2014, 50, 13845-13848. [CrossRef] [PubMed]

38. Zhang, X.; Wang, S.; Xu, L.; Feng, L.; Ji, Y.; Tao, L.; Li, S.; Wei, Y. Biocompatible polydopamine fluorescent organic nanoparticles: Facile preparation and cell imaging. Nanoscale 2012, 4, 5581-5584. [CrossRef] [PubMed]

39. Frisch, M.J.; Trucks, G.W.; Schlegel, H.B.; Scuseria, G.E.; Robb, M.A.; Cheeseman, J.R.; Scalmani, G.; Barone, V.; Mennucci, B.; Petersson, G.A.; et al. Gaussian 09, Revision, B.01; Gaussian Inc.: Wallingford, CT, USA, 2009.

40. Mei, J.; Leung, N.L.C.; Kwok, R.T.K.; Lam, J.W.Y.; Tang, B.Z. Aggregation-induced emission: Together we shine, united we soar! Chem. Rev. 2015, 115, 11718-11940. [CrossRef] [PubMed]

41. Price, W.S.; Ide, H.; Arata, Y. Self-diffusion of supercooled water to $238 \mathrm{k}$ using pgse nmr diffusion measurements. J. Phys. Chem. A 1999, 103, 448-450. [CrossRef]

42. Sarkar, S.; Mondal, A.; Tiwari, A.K.; Shunmugam, R. Unique emission from norbornene derived terpyridine-a selective chemodosimeter for G-type nerve agent surrogates. Chem. Commun. 2012, 48, 4223-4225. [CrossRef] [PubMed]

43. Yan, J.; Wang, R.; Pan, D.; Yang, R.; Xu, Y.; Wang, L.; Yang, M. Thiolactone-maleimide: A functional monomer to synthesize fluorescent aliphatic poly(amide-imide) with excellent solubility via in situ pegylation. Polym. Chem. 2016, 7, 6241-6249. [CrossRef]

44. Xu, Q.; Lee, K.M.; Wang, F.; Yoon, J. Visual detection of copper ions based on azide- and alkyne-functionalized polydiacetylene vesicles. J. Mater. Chem. 2011, 21, 15214-15217. [CrossRef]

(C) 2019 by the authors. Licensee MDPI, Basel, Switzerland. This article is an open access article distributed under the terms and conditions of the Creative Commons Attribution (CC BY) license (http://creativecommons.org/licenses/by/4.0/). 